\title{
Pengaruh Karakteristik Individu dan Pemanfaatan Teknologi Informasi Terhadap Kinerja Pegawai
}

\author{
Wayan Sri Wijayanti1), Herman Sjahruddin²), Nurlaely Razak ${ }^{3}$ \\ wayansriwijayanti@gmail.com \\ 1) Mahasiswa Program Studi Manajemen pada Sekolah Tinggi Ilmu Ekonomi Bongaya \\ Makassar \\ 2,3) Dosen Program Studi Manajemen pada Sekolah Tinggi Ilmu Ekonomi Bongaya \\ Makassar
}

\begin{abstract}
ABSTRAK
Menguji Pengaruh karakteristik individu dan pemanfaatan teknologi informasi terhadap kinerja pegawai merupakan tujuan dilakukannya penelitian ini. Pengumpulan data dilakukan dengan menggunakan teknik proportionated random sampling. Populasinya adalah seluruh pegawai tetap pada KPP Pratama Makassar Utara sejumlah 112 pegawai, sedangkan sampel yang diambil berjumlah 88 responden. Hasil analisis data dengan menggunakan teknik SEM (Structural equation modeling) WaphPLS ver. 5.0 memberikan bukti bahwa karakteristik individu berpengaruh positif dan signifikan terhadap kinerja pegawai, pada efek lainnya pemanfaatan teknologi informasi yang baik belum mampu meningkatkan kinerja pegawai.

Kata Kunci : Karakteristik Individu, Pemanfaatan Teknologi Informasi, Kinerja Pegawai
\end{abstract}

\begin{abstract}
Testing the Effect of individual characteristics and usage of information system on employee performance is the goal of this study. The data collection was done using by proportionate stratified random sampling. The population is all employees remain on 112 employees in KPP Pratama North Makassar, whereas samples taken amounted to 88 respondents. The results of data analysis using by WaphPLS ver. 5.0 provide evidence that the individual characteristics has a positive and significant effect on employees performance, on the other effects of the effective usage of information systems has been unable to improve employee performance.
\end{abstract}

Keywords: individual characteristics, usage of information system, employee performance

A. Latar Belakang

Keberhasilan sistem perpajakan nasional menuntut pegawai Kantor Pelayanan Pajak (KPP) Pratama Makassar Utara untuk lebih meningkatkan kinerja utamanya. Salah satu representasi dari keberhasilan KPP Makassar Utara ditunjukkan melalui penerimaan pajak yang diperoleh setiap tahunnya dan hanya dapat dicapai melalui kesadaran wajib pajak dalam membayar pajak mereka. Semakin tinggi kesadaran wajib pajak, semakin tinggi kinerja pegawai. 


\section{JURNAL ORGANISASI DAN MANAJEMEN}

Issue 1 (September, 2017)

Berdasarkan teorinya, kinerja individu dijelaskan melalui tiga faktor, yaitu kemampuan individu melakukan pekerjaan tersebut, tingkat usaha yang dicurahkan dan dukungan organisasi yang secara luas dalam literature manajemen diformulasikan sebagai : Kinerja (Performance / P) = Kemampuan (Ability / A) $\mathrm{x}$ Usaha (Effort / E) x Dukungan (Support / S) (Robbins, 1996, dalam Mathis dan Jackson, 2006:112, dalam Amin, dkk., 2016). Teori tersebut menjelaskan bahwa beberapa faktor penting dalam penciptaan kinerja karyawan yang tinggi dipengaruhi oleh karakteristik individu dan pemanfaatan teknologi informasi.

Fakta lapangan menunjukkan bahwa jumlah penerimaan pajak KPP Pratama Makassar Utara terendah dibandingkan KPP Pratama Makassar Barat dan KPP Pratama Makassar Selatan. Kondisi itu juga yang menentukan kinerja KPP Pratama Makassar Utara tergolong rendah dibandingkan KPP Pratama Makassar Barat dan Selatan, sehingga dipandang penting untuk menganalisis kinerja individu pegawai KPP Pratama Makassar Utara. Dalam menganalisis kinerja tersebut dipengaruhi oleh faktor - faktor karakteristik individu dan pemanfaatan teknologi informasi. Fakta lain yang diidentifikasikan bahwa pegawai KPP Pratama Makassar Utara belum sepenuhnya mampu menggunakan sistem teknologi yang baik dalam memberikan pelayanan kepada masyarakat, sementara masyarakat menuntut pelayanan yang cepat dari KPP Pratama Makassar Utara. Hal ini disebabkan oleh tingkat kemampuan pegawai KPP Pratama Makassar Utara yang belum sepenuhnya menguasai penerapan sistem teknologi informasi yang memadai dalam memberikan pelayanan kepada masyarakat. Karakteristik individu merupakan faktor internal (interpersonal) yang menggerakkan dan mempengaruhi perilaku individu yang mencakup usia, jenis kelamin, tingkat pendidikan, status perkawinan, dan masa kerja dalam organisasi (Ratih Hurriyati, 2005:79, dalam Setiawan, 2013). Karakteristik individu dapat diukur dengan Kemampuan, Minat, Nilai dan Sikap (Yuliarso, dkk., 2013, dalam Kardilla,.dkk, 2016).

Fakta lainnya di identifikasi adanya sikap kerja dari pegawai KPP Pratama Makassar Utara yang masih lamban dalam menanggapi keluhan yang dialami masyarakat untuk mendaftarkan diri sebagai wajib pajak pemula sehingga menimbulkan rasa tidak nyaman terhadap masyarakat karena terjadinya antrian panjang. Hal ini menyebabkan menurunnya tingkat kinerja pegawai KPP Pratama Makassar Utara. Berdasarkan hasil penelitian terdahulu yang dilakukan Peoni, (2014) memberikan bukti bahwa Karakteristik individu berpengaruh positif dan signifikan terhadap Kinerja karyawan, berbeda dengan hasil penelitian yang dilakukan Setiawan, (2013) bahwa Karakteristik individu berpengaruh positif dan tidak signifikan terhadap Kinerja karyawan.

Selain karakteristik individu, faktor lain yang juga mempengaruhi kinerja individu yaitu pemanfaatan teknologi informasi. Pemanfaatan teknologi informasi merupakan manfaat yang diharapkan oleh pengguna sistem informasi dalam melaksanakan tugasnya atau perilaku dalam menggunakan teknologi pada saat melakukan pekerjaan (Karmila, 2013, dalam Rachmawati, 2014). Pemanfaatan teknologi informasi dapat diukur dengan Intensitas teknologi informasi, Ketersediaan tenaga ahli, Investasi pada teknologi, Kemudahan bertukar informasi, dan Kemudahan akses bekerjasama (Zowghi, 2003, dalam Amin Hamka dkk., 2016). Fakta lain yang juga diidentifikasi berdasarkan pra penelitian bahwa masyarakat belum merasakan sepenuhnya program-program baru yang diterapkan di KPP Pratama Makassar Utara disebabkan karena kurangnya sosialisasi kepada masyarakat terhadap keunggulan dan pemanfaatan dari program yang digunakan. 


\section{JURNAL ORGANISASI DAN MANAJEMEN}

Issue 1 (September, 2017)

Hal ini didukung dengan kurang efektifnya tingkat pemantauan terhadap penyebaran program-program penting tentang pajak kepada msyarakat luas melalui media elektronik. Berdasarkan hasil penelitian terdahulu yang dilakukan Kertahadi, dkk.,(2016) memberikan bukti bahwa Pemanfaatan Teknologi Informasi berpengaruh positif dan signifikan terhadap Kinerja karyawan, berbeda dengan hasil penelitian yang dilakukan oleh Amalia, (2010) bahwa Pemanfaatan Teknologi Informasi berpengaruh positif dan tidak signifikan terhadap Kinerja karyawan.

\section{B. Tinjauan Pustaka}

\section{Pengertian karakteristik individu}

Karakteristik individu merupakan sifat pembawaan seseorang yang dapat diubah dengan lingkungan atau pendidikan (Hasibuan, 2009:55, dalam Peoni, 2014). Variabel di tingkat individu meliputi karakteristik biografis, kemampuan kepribadian dan pembelajaran. Karakteristik biografis meliputi usia, jenis kelamin, status perkawinan, banyaknya tanggungan, dan masa kerja dengan suatu organisasi dari karyawan itu. Sedangkan yang termasuk kemampuan adalah kemampuan fisik dan mental (Robbins, 2007:78, dalam Moses, 2014). Berdasarkan pendapat (Yuliarso, dkk., 2013, dalam Kardilla, dkk.,2016), maka indikator pengukuran karakteristik individu yang digunakan dalam penelitian ini antara lain: kemampuan, minat, nilai dan sikap

\section{Pengertian pemanfaatan teknologi informasi}

Pengolahan data menjadi suatu informasi dengan bantuan komputer jelas akan lebih meningkatkan nilai dari informasi yang dihasilkan. Teknologi informasi adalah suatu studi, perancangan, pengembangan, implementasi, dukungan atau manajemen sistem informasi berbasis komputer, khususnya aplikasi perangkat lunak dan perangkat keras komputer (Sutarman, 2009: 13, dalam Aminah, 2016). Pemanfaatan teknologi informasi merupakan manfaat yang diharapkan oleh pengguna sistem informasi dalam melaksanakan tugasnya atau perilaku dalam menggunakan teknologi pada saat melakukan pekerjaan (Thomson et.al.; dalam Wijana, 2007, dalam Chintya, 2015). Pemanfaatan teknologi informasi diukur menggunakan beberapa indikator antara lain sebagai berikut (Zowghi, 2003, dalam Amin, dkk., 2016): Intensitas teknologi informasi, Ketersediaan tenaga ahli, Investasi pada teknologi, Kemudahan bertukar Informasi dan Kemudahan akses bekerja sama.

\section{Pengertian Kinerja Pegawai}

Implementasi kinerja dilakukan oleh sumber daya manusia yang memiliki kemampuan, kompetensi, motivasi dan kepentingan (Wibowo, 2007:4, dalam Suwati, 2013). Kinerja adalah hasil kerja secara kualitas dan kuantitas yang dicapai oleh seorang pegawai dalam melaksanakan tugasnya sesuai dengan tanggung jawab yang diberikan kepadanya (Sedarmayanti, 2009:51, dalam Mandasari, 2016). Penjelasan terhadap hasil kinerja individu dijelaskan melalui tiga faktor, yaitu kemampuan individu melakukan pekerjaan tersebut, tingkat usaha yang dicurahkan dan dukungan organisasi yang secara luas dalam literature manajemen diformulasikan sebagai : Kinerja (Performance / P) = Kemampuan (Ability / A) x Usaha (Effort / E) x Dukungan (Support / S) (Robbins, 1996, dalam Mathis dan Jackson, 2006:112, dalam Amin, dkk., 2016). Teori tersebut menjelaskan bahwa beberapa faktor penting dalam penciptaan kinerja karyawan yang tinggi dipengaruhi oleh karakteristik individu dan pemanfaatan teknologi informasi. Ada 4 
Issue 1 (September, 2017)

faktor untuk mengukur kinerja individu adalah sebagai berikut (Maqfiranti, dkk., 2014, dalam Amin, dkk., 2016): Kualitas kerja, Kuantitas kerja, Kreativitas kerja dan Pengetahuan pekerjaan

\section{Metode Penelitian}

Penelitian ini termasuk penelitian metode deskriptif kuantitatif yang bertujuan untuk menjelaskan suatu fenomena empiris yang disertai data statistik dan pola hubungan antara variabel. Penelitian ini menggunakan analisis SEM (Structural equation modeling) dibantu dengan WaphPLS Ver. 5.0 sebagai peralatan penelitian.

D. Hasil Penelitian

\section{Evaluasi Model Pengukuran (Outer Model) Model 1}

Evaluasi outer model dilakukan melalui 3 kriteria yaitu convergent validity, discriminant validity dan composite reliability. Berikut ini adalah hasil pengolahan data:

a) Convergent Validity (Validitas Konvergen)

Convergent validity dari model pengukuran dapat dilihat dari korelasi antara skor indikator dengan skor konstruknya (loading factor) dengan kriteria nilai loading factor dari setiap indikator lebih besar dari 0,70 dapat dikatakan valid. Selanjutnya untuk nilai p-value apabila $<0,05$ dianggap signifikan. Loading factor antara 0,400,70 harus tetap dipertimbangkan untuk dipertahankan. Selanjutnya dijelaskan pula bahwa, indikator dengan loading $<0,40$ dihapus dari model. Penghapusan indikator dengan loading antara 0,40-0,70 dilakukan apabila indikator tersebut dapat meningkatkan AVE dan composite reliability diatas nilai batasannya. Nilai batasan untuk AVE 0,50 dan composite reliability adalah 0,50 (Machfud dan Dwi, 2013: 66 dalam Ovi Arista, 2015). Hasil pengolahan Convergent Validity dapat dilihat pada tabel berikut ini:

Tabel 1. Hasil output combined loadings and cross-loading (model 1)

\begin{tabular}{|l|l|l|l|l|l|}
\multicolumn{1}{|c|}{ MODEL 1 } & \multicolumn{1}{|c|}{ KI } & \multicolumn{1}{c|}{ PTI } & \multicolumn{1}{c|}{ KP } & \multicolumn{1}{c|}{ SE } & \multicolumn{1}{c|}{ P value } \\
\hline $\mathbf{X}_{11}$ & $(0.794)$ & -0.126 & -0.053 & 0.085 & $<0.001$ \\
\hline $\mathbf{X}_{12}$ & $(0.785)$ & 0.046 & -0.087 & 0.085 & $<0.001$ \\
\hline $\mathbf{X}_{13}$ & $(0.801)$ & 0.140 & 0.064 & 0.085 & $<0.001$ \\
\hline $\mathbf{X}_{14}$ & $(0.801)$ & -0.060 & 0.073 & 0.085 & $<0.001$ \\
\hline $\mathbf{X}_{21}$ & -0.543 & $(0.342)$ & 0.598 & 0.097 & $<0.001$ \\
\hline $\mathbf{X}_{22}$ & 0.894 & $(0.591)$ & -0.784 & 0.090 & $<0.001$ \\
\hline $\mathbf{X}_{23}$ & -0.034 & $(0.682)$ & -0.076 & 0.087 & $<0.001$ \\
\hline $\mathbf{X}_{24}$ & -0.351 & $(0.756)$ & 0.081 & 0.086 & $<0.001$ \\
\hline $\mathbf{X}_{25}$ & -0.064 & $(0.854)$ & 0.292 & 0.083 & $<0.001$ \\
\hline $\mathbf{Y}_{11}$ & 0.204 & 0.018 & $(0.814)$ & 0.084 & $<0.001$ \\
\hline $\mathbf{Y}_{12}$ & 0.085 & 0.018 & $(0.788)$ & 0.085 & $<0.001$ \\
\hline $\mathbf{Y}_{13}$ & -0.135 & 0.127 & $(0.719)$ & 0.087 & $<0.001$ \\
\hline $\mathbf{Y}_{14}$ & -0.167 & -0.148 & $(0.812)$ & 0.084 & $<0.001$ \\
\hline Sum & & & & \\
\hline
\end{tabular}

Sumber: Data primer (diolah WarphPLS Ver 5.0, 2017) 


\section{JURNAL ORGANISASI DAN MANAJEMEN}

Issue 1 (September, 2017)

Berdasarkan hasil pengolahan data diatas maka dapat dijelaskan bahwa Convergent validity (uji validitas) untuk konstruk karakteristik individu $\left(\mathrm{X}_{1}\right)$ semua indikator tersebut memenuhi standar Convergent Validity dengan nilai $>0.70$ dan $P$ value juga telah memenuhi syarat yaitu memiliki nilai sebesar $<0,001(<0,05)$ sehingga indikator-indikator tersebut tidak dikeluarkan pada model 2. Convergent validity (uji validitas) untuk konstruk pemanfaatan teknologi informasi $\left(\mathrm{X}_{2}\right)$ menunjukkan bahwa terdapat 2 indikator yang tidak memenuhi standar Convergent validity yaitu, $\mathrm{X}_{21}$ dan $\mathrm{X}_{22}<0.70$, sehingga indikator tersebut harus dikeluarkan dari model, untuk indikator $\mathrm{X}_{23}$ tidak dikeluarkan dari model karena merujuk pada pendapat (Sofyan dan Heri, 2011: 18 dalam Hasanuddin,R., dan Sjahruddin, H. 2017) nilai standarized loading factor, diatas 0,5 dapat diterima, sedangkan dibawah 0,5 dikeluarkan dari model. Sehingga tidak ada alasan yang kuat untuk mengeluarkan indikator tersebut dan untuk indikator $\mathrm{X}_{24}$ dan $\mathrm{X}_{25}$ memenuhi standar Convergent Validity dengan nilai $>0.70$ dan P-value juga telah memenuhi syarat yaitu memiliki nilai sebesar $<0,001(<0,05)$ dalam semua indikator.

Convergent validity untuk konstruk kinerja pegawai $(\mathrm{Y})$ bahwa semua indikator tersebut memenuhi standar Convergent Validity dengan nilai $>0.70$ dan Pvalue juga telah memenuhi syarat yaitu memiliki nilai sebesar $<0,001 \quad(<0,05)$. Berdasarkan hasil tersebut ditemukan bahwa masih terdapat indikator dari variabel pemanfaatan teknologi informasi $\left(\mathrm{X}_{2}\right)$ yang tidak memenuhi standar Convergent validity (uji validitas) yaitu, $\mathrm{X}_{21}$ dan $\mathrm{X}_{22}$ dengan nilai sebesar $\mathrm{X}_{21}=0,342<0.70$ dan $\mathrm{X}_{22}=0,591<0.70$, sehingga terdapat alasan yang cukup kuat untuk mengeluarkannya dari model dan kemudian melanjutkannya dengan model 2.

\section{b) Uji Composite reliability}

Penelitian ini menggunakan tiga variabel laten (variabel yang tidak terukur) yaitu variabel karakteristik individu $\left(\mathrm{X}_{1}\right)$ dan pemanfaatan teknologi informasi $\left(\mathrm{X}_{2}\right)$ serta kinerja pegawai (Y). Suatu variabel yang dipandang mampu (handal) dalam menjelaskan data dari variabel tersebut, pengujiannya dapat dilihat pada nilai composite reliability dan Cronbach's Alpha $>$ 0,60, untuk itu dapat diperlihatkan pada tabel berikut:

Tabel 2. Latent variable coefficients (composite reliability) (model 1)

\begin{tabular}{|c|c|c|c|}
\hline MODEL 1 & KI & PTI & KP \\
\hline R-Squared & & & 0,657 \\
\hline Composite reliab. & 0,873 & 0,790 & 0,864 \\
\hline Cronbach's Alpha & 0,806 & 0,662 & 0,790 \\
\hline Avg. Var. Extrac. & 0,632 & 0,446 & 0,615 \\
\hline Full Collin. VIF & 3,318 & 1,883 & 2,847 \\
\hline Q-Squared & & & 0,660 \\
\hline
\end{tabular}

Sumber: Data primer (diolah WarphPLS Ver 5.0, 2017)

Nilai composite reliability untuk variabel karakteristik individu sebesar $0,873>0,60$ sedangkan untuk variabel pemanfaatan teknologi informasi sebesar $0,790>0,60$ dan yang terakhir pada variabel kinerja pegawai sebesar 0,864 >0,60. Selanjutnya untuk Cronbach's Alpha pada variabel karakteristik individu sebesar $0,806>0,60$ sedangkan untuk variabel pemanfaatan teknologi informasi sebesar $0,662>0,60$ dan yang terakhir pada variabel kinerja pegawai sebesar 0,790 > 0,60. Untuk nilai Average Variances Extracted (AVE)/ nilai variasi rata-rata pada variabel karakteristik individu sebesar 0,632 $>0,50$ sedangkan untuk variabel pemanfaatan 
Issue 1 (September, 2017)

teknologi informasi sebesar 0,446 $<0,50$ dan yang terakhir pada variabel kinerja pegawai sebesar $0,615>0,50$.

Berdasarkan hasil tersebut maka nilai yang belum memenuhi kriteria pengujian ditemukan pada nilai variasi rata-rata (AVE) untuk variabel pemanfaatan teknologi informasi, sehingga terdapat cukup alasan yang kuat untuk mengujinya kembali pada model 2 .

\section{Evaluasi Model Pengukuran (Outer Model) Model 2}

Pada model 2 yaitu evaluasi outer model dilakukan melalui 3 kriteria yaitu convergent validity, discriminant validity dan composite reliability. Berikut ini adalah hasil pengolahan data:

a) Convergent Validity (Validitas Konvergen)

Convergent validity dari model pengukuran dapat dilihat dari korelasi antara skor indikator dengan skor konstruknya (loading factor) dengan kriteria nilai loading factor dari setiap indikator lebih besar dari 0,70 dapat dikatakan valid. Selanjutnya untuk nilai p-value apabila $<0,05$ dianggap signifikan Hasil pengolahan Convergent Validity dapat dilihat pada tabel berikut ini:

Tabel 3. Hasil output combined loadings and cross-loading (model 2)

\begin{tabular}{|l|l|l|l|l|l|}
\multicolumn{1}{|c|}{ MODEL 2 } & \multicolumn{1}{c|}{ KI } & \multicolumn{1}{c|}{ PTI } & \multicolumn{1}{c|}{ KP } & \multicolumn{1}{c|}{ SE } & \multicolumn{1}{c|}{ P value } \\
\hline $\mathbf{X}_{\mathbf{1 1}}$ & $(0.794)$ & -0.045 & -0.099 & 0.085 & $<0.001$ \\
\hline $\mathbf{X}_{\mathbf{1 2}}$ & $(0.785)$ & 0.001 & 0.033 & 0.085 & $<0.001$ \\
\hline $\mathbf{X}_{\mathbf{1 3}}$ & $(0.801)$ & 0.072 & 0.028 & 0.085 & $<0.001$ \\
\hline $\mathbf{X}_{\mathbf{1 4}}$ & $(0.801)$ & -0.029 & 0.038 & 0.085 & $<0.001$ \\
\hline $\mathbf{X}_{\mathbf{2 3}}$ & 0.150 & $(0.729)$ & -0.261 & 0.086 & $<0.001$ \\
\hline $\mathbf{X}_{\mathbf{2 4}}$ & -0.161 & $(0.786)$ & -0.052 & 0.085 & $<0.001$ \\
\hline $\mathbf{X}_{\mathbf{2 5}}$ & 0.020 & $(0.851)$ & 0.272 & 0.083 & $<0.001$ \\
\hline $\mathbf{Y}_{\mathbf{1 1}}$ & 0.075 & 0.051 & $0.814)$ & 0.084 & $<0.001$ \\
\hline $\mathbf{Y}_{\mathbf{1 2}}$ & 0.146 & -0.025 & $(0.788)$ & 0.085 & $<0.001$ \\
\hline $\mathbf{Y}_{\mathbf{1 3}}$ & -0.181 & 0.195 & $(0.719)$ & 0.087 & $<0.001$ \\
\hline $\mathbf{Y}_{\mathbf{1 4}}$ & -0.056 & -0.200 & $(0.812)$ & 0.084 & $<0.001$ \\
\hline
\end{tabular}

Sumber: Data primer (diolah WarphPLS Ver 5.0, 2017)

Hasil pada tabel diatas, menunjukkan hasil pengujian Convergent validity untuk model 2, dimana pada model 1 sebelumnya terdapat beberapa indikator pada variabel karakteristik individu, pemanfaatan teknologi informasi dan kinerja pegawai yang tidak memenuhi standar Convergent validity sehingga dilakukan pengujian model 2. Pada pengujian model 2 diatas, semua indikator yang tidak memenuhi standar Convergent validity telah dikeluarkan dari model, sehingga pengujian Convergent validity pada model 2 telah memenuhi standar Convergent Validity dengan nilai $>0.70$ dan $P$-value juga telah memenuhi syarat yaitu memiliki nilai sebesar $<0,001(<0,05)$ untuk seluruh indikator dari variabel karakteristik individu, pemanfaatan teknologi informasi dan kinerja pegawai.

b) Uji Composite reliability

Suatu variabel yang dipandang mampu (handal) dalam menjelaskan data dari variabel tersebut, pengujiannya dapat dilihat pada nilai composite reliability dan Cronbach's Alpha $<0,60$, untuk itu dapat diperlihatkan pada tabel berikut: 


\section{JURNAL ORGANISASI DAN MANAJEMEN}

Issue 1 (September, 2017)

Tabel 4. Latent variable coefficients (composite reliability) (model 2)

\begin{tabular}{|c|c|c|c|}
\hline MODEL 2 & KI & PTI & KP \\
\hline R-Squared & & & 0,658 \\
\hline Composite reliab. & 0,873 & 0,833 & 0,864 \\
\hline Cronbach's Alpha & 0,806 & 0,697 & 0,790 \\
\hline Avg. Var. Extrac. & 0,632 & 0,625 & 0,615 \\
\hline Full Collin. VIF & 3,100 & 1,717 & 2,893 \\
\hline Q-Squared & & & 0,658 \\
\hline
\end{tabular}

Sumber: Data primer (diolah WarphPLS Ver 5.0, 2017)

Nilai composite reliability untuk variabel karakteristik individu sebesar $0,873>0,60$ sedangkan untuk variabel pemanfaatan teknologi informasi sebesar $0,833>0,60$ dan yang terakhir pada variabel kinerja pegawai sebesar 0,864 >0,60. Selanjutnya untuk Cronbach's Alpha pada variabel karakteristik individu sebesar $0,806>0,60$ sedangkan untuk variabel pemanfaatan teknologi informasi sebesar $0,697>0,60$ dan yang terakhir pada variabel kinerja pegawai sebesar 0,790 >0,60. Untuk nilai Average Variances Extracted (AVE)/ nilai variasi rata-rata pada variabel karakteristik individu sebesar 0,632 >0,50 sedangkan untuk variabel pemanfaatan teknologi informasi sebesar 0,625 $<0,50$ dan yang terakhir pada variabel kinerja pegawai sebesar $0,615>0,50$.

Berdasarkan hasil tersebut maka keseluruhan nilai memenuhi kriteria pengujian, sehingga terdapat cukup alasan yang kuat untuk mengujinya kembali pada model 2. memiliki alasan yang kuat untuk dianalisis lebih lanjut dimodel 2 .

Tabel 5. Nilai AVE (Average Variance Extracted) (model 2)

\begin{tabular}{|l|l|l|}
\hline Variabel Laten & Nilai AVE & Kriteria \\
\hline KI & 0,632 & $>0,50$ \\
\hline PTI & 0,625 & $>0,50$ \\
\hline KP & 0,615 & $>0,50$ \\
\hline
\end{tabular}

Sumber: Data primer (diolah WarphPLS Ver 5.0, 2017)

Berdasarkan hasil tersebut ketiga konstruk telah memenuhi convergent validity. Karakteristik individu dengan nilai $0,632>0,50$, Pemanfaatan teknologi informasi dengan nilai 0,625 juga telah memenuhi nilai $>0,50$ dan Kinerja pegawai memiliki nilai $0,615>0,50$. Kesimpulannya keseluruhan variabel telah memenuhi kriteria convergent validity.

Selanjutnya analisis mengenai standard error, yang dituliskan dengan huruf SE. Semakin kecil standard error dari suatu indikator maka semakin baik atau semakin layak. Standard error yang besar menunjukkan adanya ketidaklayakan model yang disusun, dan diharapkan nilainya relatif kecil yaitu dibawah 0,5 atau 0,4 dan tidak boleh bernilai negatif (Konsultan Statistik, 2009, dalam Ovi Arista, 2015). Berikut ini disajikan dalam tabel untuk masing-masing indikator: 
Tabel 6. Hasil Standard Error (model 2)

\begin{tabular}{|c|c|c|c|}
\hline Indikator & $\begin{array}{c}\text { SE } \\
\text { (Standard Error) }\end{array}$ & Kriteria & Keterangan \\
\hline $\mathbf{X}_{\mathbf{1 1}}$ & 0.085 & $<0,4-0,5$ dan tidak negatif & Terpenuhi \\
\hline $\mathbf{X}_{\mathbf{1 2}}$ & 0.085 & $<0,4-0,5$ dan tidak negatif & Terpenuhi \\
\hline $\mathbf{X}_{\mathbf{1 3}}$ & 0.085 & $<0,4-0,5$ dan tidak negatif & Terpenuhi \\
\hline $\mathbf{X}_{\mathbf{1 4}}$ & 0.085 & $<0,4-0,5$ dan tidak negatif & Terpenuhi \\
\hline $\mathbf{X}_{\mathbf{2 3}}$ & 0.086 & $<0,4-0,5$ dan tidak negatif & Terpenuhi \\
\hline $\mathbf{X}_{\mathbf{2 4}}$ & 0.085 & $<0,4-0,5$ dan tidak negatif & Terpenuhi \\
\hline $\mathbf{X}_{\mathbf{2 5}}$ & 0.083 & $<0,4-0,5$ dan tidak negatif & Terpenuhi \\
\hline $\mathbf{Y}_{\mathbf{1 1}}$ & 0.084 & $<0,4-0,5$ dan tidak negatif & Terpenuhi \\
\hline $\mathbf{Y}_{\mathbf{1 2}}$ & 0.085 & $<0,4-0,5$ dan tidak negatif & Terpenuhi \\
\hline $\mathbf{Y}_{\mathbf{1 3}}$ & 0.087 & $<0,4-0,5$ dan tidak negatif & Terpenuhi \\
\hline $\mathbf{Y}_{\mathbf{1 4}}$ & 0.084 & $<0,4-0,5$ dan tidak negatif & Terpenuhi \\
\hline
\end{tabular}

Sumber: Data primer (diolah WarphPLS Ver 5.0, 2017)

Berdasarkan tabel di atas, dapat disimpulkan bahwa keseluruhan indikator memiliki kelayakan model. Variabel karakteristik individu (KI), pemanfaatan teknologi informasi (PTI) dan kinerja pegawai (KP) memilki nilai standard error yang sesuai kriteria yaitu $<0,5$ dan dianggap layak.

\section{c) Discriminant Validity}

Discriminant validity dinilai dari cross loading pengukuran dengan konstruk. Dapat dilihat dengan melihat loading konstruk laten, yang akan memprediksi indikatornya lebih baik daripada konstruk lainnya. Jika korelasi konstruk dengan pokok pengukuran (setiap indikator) lebih besar daripada ukuran konstruk lainnya maka validitas diskriminan terpenuhi.

Tabel 7. Nilai loading konstruk laten indikator ke konstruk lainnya

\begin{tabular}{|c|c|c|c|c|}
\hline \multirow{2}{*}{ Indikator } & \multicolumn{2}{|c|}{ Nilai Loading ke konstruk lainnya } & \multirow{2}{*}{ Keterangan } \\
\cline { 2 - 4 } & KI & PTI & KP & Terpenuhi \\
\hline $\mathbf{X}_{11}$ & $(0.794)$ & -0.045 & -0.099 & Terpenuhi \\
$\mathbf{X}_{12}$ & $(0.785)$ & 0.001 & 0.033 & Terpenuhi \\
$\mathbf{X}_{13}$ & $(0.801)$ & 0.072 & 0.028 & Terpenuhi \\
$\mathbf{X}_{14}$ & $(0.801)$ & -0.029 & 0.038 & Terpenuhi \\
$\mathbf{X}_{23}$ & 0.150 & $(0.729)$ & -0.261 & Terpenuhi \\
$\mathbf{X}_{24}$ & -0.161 & $(0.786)$ & -0.052 & Terpenuhi \\
$\mathbf{X}_{\mathbf{2 5}}$ & 0.020 & $(0.851)$ & 0.272 & Terpenuhi \\
\hline $\mathbf{Y}_{11}$ & 0.075 & 0.051 & $(0.814)$ & Terpenuhi \\
$\mathbf{Y}_{12}$ & 0.146 & -0.025 & $(0.788)$ & Terpenuhi \\
$\mathbf{Y}_{13}$ & -0.181 & 0.195 & $(0.719)$ & Terpenuhi \\
$\mathbf{Y}_{14}$ & -0.056 & -0.200 & $(0.812)$ & \\
\hline
\end{tabular}

Sumber: Data primer (diolah WarphPLS Ver 5.0, 2017)

Author : Wayan Sri Wijayanti dkk. (September, 2017). 14-28 


\section{JURNAL ORGANISASI DAN MANAJEMEN}

Issue 1 (September, 2017)

Berdasarkan data di atas, keseluruhan indikator telah memenuhi kriteria validitas diskriminan. Variabel karakteristik individu yang memiliki 4 indikator yang dilambangkan dengan $\mathrm{X}_{11}, \mathrm{X}_{12}, \mathrm{X}_{13}$ dan $\mathrm{X}_{14}$. Untuk indikator $\mathrm{X}_{11}$ memiliki nilai loading 0,794 yang nilai loading-nya lebih besar dari loading ke konstruk lain yaitu -0,045 dan -0,099 dan ke 3 indikator karakteristik individu lainnya juga memiliki nilai loading yang lebih besar dari nilai loading ke konstruk lain.

Variabel pemanfaatan teknologi informasi yang memiliki 3 indikator yang dilambangkan dengan $\mathrm{X}_{23}, \mathrm{X}_{24}$ dan $\mathrm{X}_{25}$. Untuk indikator $\mathrm{X}_{23}$ memiliki nilai loading 0,729 yang nilai loading-nya lebih besar dari loading ke konstruk lain yaitu 0,150 dan -0,261 dan ke 2 indikator pemanfaatan teknologi informasi lainnya juga memiliki nilai loading yang lebih besar dari nilai loading ke konstruk lain

Variabel kinerja pegawai memiliki 4 indikator yang dilambangkan dengan $\mathrm{Y}_{11}, \mathrm{Y}_{12}, \mathrm{Y}_{13}$ dan $\mathrm{Y}_{14}$. Untuk indikator $\mathrm{Y}_{11}$ memiliki nilai loading 0,814 yang nilai loading-nya lebih besar dari loading ke konstruk lain yaitu 0,075 dan 0,051 dan ke 3 indikator pemanfaatan teknologi informasi lainnya juga memiliki nilai loading yang lebih besar dari nilai loading ke konstruk lain. Berdasarkan uraian tersebut, dapat disimpulkan bahwa keseluruhan indikator telah memenuhi kriteria validitas diskriminan.

\section{Evaluasi Model Struktural (Inner Model)}

Tahap selanjutnya adalah melakukan evaluasi struktural (inner model) yang meliputi uji kecocokan model (model fit), path coefficient, dan $\mathrm{R}^{2}$. Pada uji kecocokan model terdapat 3 indeks pengujian, yaitu average path coefficient (APC), average $R$ squared (ARS) dan average varians factor (AVIF) dengan kriteria APC dan ARS diterima dengan syarat $p-$ value $<0,05$ dan AVIF $<5$ (Mahfud Sholihin dan Dwi Ratmono, 2013: 61). Berikut ini adalah hasil output model fit indices yang disajikan dalam bentuk tabel yaitu:

Tabel 8. Hasil output model fit indices

\begin{tabular}{|c|l|l|l|l|}
\hline & \multicolumn{1}{|c|}{ Indeks } & \multicolumn{1}{|c|}{$\boldsymbol{P}$-Value } & \multicolumn{1}{c|}{ Kriteria } & \multicolumn{1}{c|}{ Keterangan } \\
\hline APC & 0,429 & $\mathrm{P}<0,001$ & $\mathrm{P}<0,05$ & Diterima \\
\hline ARS & 0,658 & $\mathrm{P}<0,001$ & $\mathrm{P}<0,05$ & Diterima \\
\hline AVIF & $\begin{array}{l}1,727 \text { Acceptable if } \\
<5\end{array}$ & & $\mathrm{AVIF}<5$ & Diterima \\
\hline
\end{tabular}

Sumber: Data primer (diolah WarphPLS Ver 5.0, 2017)

Hasil output di atas, menjelaskan bahwa APC memiliki indeks sebesar 0,429 dengan nilai $p$ - value $<0,001$. Sedangkan ARS memiliki indeks sebesar 0,658 dengan $p$-value $<0,001$. Berdasarkan kriteria, APC sudah memenuhi kriteria karena memiliki nilai $p<0,001$. Begitu pula dengan nilai $p$ dari ARS yaitu $p<0,001$. Nilai AVIF yang harus $<5$ sudah terpenuhi karena berdasarkan data tersebut AVIF nilainya 1,727. Dengan demikian, maka inner model dapat diterima.

a. Hasil Uji Hipotesis

Hasil korelasi antar konstruk diukur dengan melihat path coefficients dan tingkat signifikansinya yang kemudian dibandingkan dengan hipotesis penelitian yang terdapat di bab dua. Tingkat signifikansi yang dipakai dalam penelitian ini adalah sebesar $5 \%$. Berikut ini hipotesis yang dimaksudkan untuk membuktikan kebenaran dugaan penelitian yang terdiri dari tiga hipotesis, yaitu: 


\section{JURNAL ORGANISASI DAN MANAJEMEN}

Issue 1 (September, 2017)

$\mathrm{H}_{1}=$ Karakteristik individu berpengaruh positif dan signifikan terhadap kinerja pegawai pada KPP Pratama Makassar Utara.

$\mathrm{H}_{2}=$ Pemanfaatan teknologi informasi berpengaruh positif dan signifikan terhadap kinerja pegawai pada KPP Pratama Makassar Utara.

$\mathrm{H}_{3}=$ Karakteristik individu dominan berpengaruh positif dan signifikan terhadap kinerja pegawai pada KPP Pratama Makassar Utara.

Berikut ini merupakan gambaran hasil penelitian yang telah diperoleh berdasarkan pengolahan data:

Gambar 1. Full Model

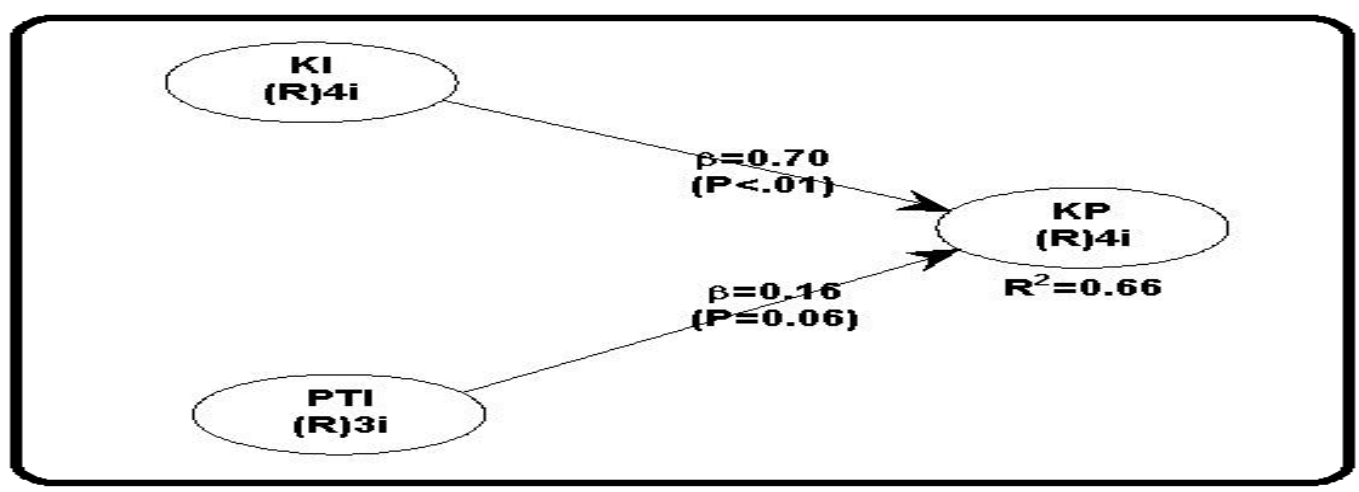

Sumber: Hasil pengolahan WarphPLS Ver. 5,0 (2017)

Keterangan gambar : KI : Karakteristik Individu

PTI : Pemanfaatan Teknologi Informasi

KP : Kinerja Pegawai

Berikut ini tabel hasil pengujian hipotesis yang telah diperoleh berdasarkan pengolahan data:

Tabel 9. Pengujian hipotesis

\begin{tabular}{|c|c|c|c|c|c|c|c|}
\hline \multirow{2}{*}{ Variabel } & \multicolumn{3}{|c|}{ KI } & \multicolumn{3}{|c|}{ PTI } & KP \\
\cline { 2 - 7 } & $\begin{array}{c}\text { Path } \\
\text { Coeffiecient }\end{array}$ & $\begin{array}{c}\text { Effect } \\
\text { size for } \\
\text { path }\end{array}$ & P-value & $\begin{array}{c}\text { Path } \\
\text { Coeffiecient }\end{array}$ & $\begin{array}{c}\text { Effect } \\
\text { size for } \\
\text { path }\end{array}$ & P-value & \\
\hline KI & - & - & - & - & - & - & - \\
\hline PTI & - & - & - & - & - & - & - \\
\hline KP & 0.701 & 0,562 & $<0.001$ & 0.157 & 0,096 & 0.063 & - \\
\hline
\end{tabular}

Sumber: Data primer (diolah WarphPLS Ver 5.0, 2017)

Hasil output di atas, menjelaskan bahwa path coefficients untuk variabel karakteristik individu terhadap kinerja pegawai memiliki indeks sebesar 0,701 dengan nilai $p$-value $<0,001$ dan nilai effect size for path 0,562 sedangkan untuk path coefficients variabel pemanfaatan teknologi informasi terhadap kinerja pegawai memiliki indeks sebesar 0,157 dengan $p$-value 0,063 nilai effect size for path 0,096.

Setelah melakukan uji hipotesis, berikut ini tabel yang merangkum uji hipotesis-hipotesis tersebut : 


\section{JURNAL ORGANISASI DAN MANAJEMEN}

Issue 1 (September, 2017)

Tabel 10. Hasil uji hipotesis

\begin{tabular}{|l|l|l|c|c|}
\hline \multicolumn{1}{|c|}{ Hipotesis } & \multicolumn{1}{|c|}{ Independen } & \multicolumn{1}{c|}{ Dependen } & p-values & Keputusan \\
\hline $\mathrm{H}_{1}$ & Kinerja Pegawai & Karakteristik Individu & $<0,001$ & Diterima \\
\hline $\mathrm{H}_{2}$ & Kinerja Pegawai & $\begin{array}{l}\text { Pemanfaatan Teknologi } \\
\text { Informasi }\end{array}$ & $<0,063$ & Ditolak \\
\hline $\mathrm{H}_{3}$ & Kinerja Pegawai & $\begin{array}{l}\text { Karakteristik Individu dan } \\
\text { Pemanfaatan Teknologi } \\
\end{array}$ & $\begin{array}{c}\text { Nilai } 0,701> \\
\text { dari nilai } \\
0,157\end{array}$ & Diterima \\
\end{tabular}

Sumber: Data primer (diolah WarphPLS Ver 5.0, 2017)

Berdasarkan tabel hasil uji hipotesis di atas, dapat diperoleh:

1. Uji hipotesis 1 diterima, artinya variabel karakteristik individu memiliki pengaruh positif dan signifikan terhadap kinerja pegawai pada KPP Pratama Makassar Utara. Hal ini ditunjukkan dengan nilai beta $(\beta)$ sebesar 0,701 dengan nilai $p$-value $<0.001$.

2. Uji hipotesis 2 ditolak, artinya variabel pemanfaatan teknologi informasi memiliki pengaruh positif dan tidak signifikan terhadap kinerja pegawai pada KPP Pratama Makassar Utara. Hal ini ditunjukkan dengan nilai beta ( $\beta$ ) sebesar 0,157 dengan nilai $p$-value 0,063.

3. Uji hipotesis 3 diterima, artinya variabel karakteristik individu dominan memiliki pengaruh positif dan signifikan terhadap kinerja pegawai pada KPP Pratama Makassar Utara. Hal ini ditunjukkan dengan variabel karakteristik individu memiliki nilai lebih tinggi yaitu nilai beta $(\beta)$ sebesar 0,701 dengan nilai $p$-value $<0.001$ dibandingkan dengan variabel pemanfaatan teknologi informasi dengan nilai beta $(\beta)$ sebesar 0,157 dan nilai $p$-value 0,063 .

\section{b. Uji besaran pengaruh variabel independen terhadap variabel dependen}

Pengujian besaran pengaruh variabel independen terhadap variabel dependen dapat ditunjukkan pada tabel berikut

Tabel 11. Ringkasan model (model summary)

\begin{tabular}{|l|c|c|c|}
\hline \multicolumn{1}{|c|}{ Pengukuran } & KI & PTI & KP \\
\hline R-squared & & & 0.658 \\
\hline Adj. R-squared & & & 0.650 \\
\hline Composite reliab. & 0.873 & 0.833 & 0.864 \\
\hline Cronbach's Alpha & 0.806 & 0.697 & 0.790 \\
\hline Avg. Var. Extrac. & 0.632 & 0.625 & 0.615 \\
\hline
\end{tabular}

Sumber: Data primer (diolah WarphPLS Ver 5.0, 2017)

Berdasarkan tabel diatas besaran pengaruh nilai $R$-squared pada variabel karakteristik individu dan variabel pemanfaatan teknologi informasi terhadap kinerja pegawai adalah $0,658(65,8 \%)$ dan sisanya $34,2 \%$ dipengaruhi oleh variabel lain yang tidak dianalisis dalam penelitian ini seperti motivasi kerja, disiplin kerja, dan variabel lainnya. 


\section{JURNAL ORGANISASI DAN MANAJEMEN}

Issue 1 (September, 2017)

\section{c. Pengaruh Karakteristik Individu Terhadap Kinerja Pegawai}

Berdasarkan hasil penelitian, ditemukan bahwa karakteristik individu memiliki pengaruh terhadap kinerja pegawai. Hasil ini sama dengan teori atau temuan dalam penelitian sebelumnya oleh Peoni, (2014) memberikan bukti bahwa Karakteristik individu berpengaruh positif dan signifikan terhadap Kinerja karyawan. Dalam penelitian ini dapat dilihat dari nilai koefisien beta yang menunjukkan bahwa semakin baik karakteristik individu maka semakin tinggi kinerja pegawai yaitu dengan nilai beta $(\beta)$ sebesar 0,701 .

Hal ini menunjukkan bahwa variabel karakteristik individu dapat memengaruhi peningkatan kinerja pegawai kearah yang lebih tinggi. Penyebab positif dan signifikannya pengaruh karakteristik individu terhadap kinerja pegawai diakibatkan karena pegawai dalam bekerja mengeluarkan seluruh kemampuan yang dimilikinya sehingga berdampak pada tingginya ketelitian pegawai dalam menyelesaikan pekerjaan tersebut. Kondisi tersebut didukung dengan pemahaman pegawai yang tinggi terhadap tugas yang diberikan dan kemampuan pegawai menyelesaikan pekerjaan secara tepat waktu sehingga berdampak nyata terhadap tuntutan pekerjaan untuk dapat diselesaikan dengan cepat dan sesuai dengan standar kerja yang ditetapkan pada KPP Pratama Makassar Utara.

\section{d. Pengaruh Pemanfaatan Teknologi Informasi Terhadap Kinerja Pegawai}

Berdasarkan hasil penelitian, ditemukan bahwa pemanfaatan teknologi informasi memiliki pengaruh terhadap kinerja pegawai. Hasil ini sama dengan teori atau temuan dalam penelitian Amalia dan Rohman, (2010) bahwa Pemanfaatan Teknologi Informasi berpengaruh positif dan tidak signifikan terhadap Kinerja karyawan. Dalam penelitian ini dapat dilihat dari nilai koefisien beta yang menunjukkan bahwa pemanfaatan teknologi informasi memiliki pengaruh positif dan tidak signifikan terhadap kinerja pegawai yaitu dengan nilai beta $(\beta)$ sebesar 0,157 .

Hal ini menunjukkan bahwa variabel pemanfaatan teknologi informasi belum mampu memengaruhi peningkatan kinerja pegawai. Penyebab positif dan tidak signifikannya pengaruh pemanfaatan teknologi informasi kinerja pegawai diakibatkan karena pegawai dalam menyelesaikan pekerjaan dilakukan dengan baik diakibatkan karena adanya inovasi yang berdampak pada solidaritas pegawai yang senantiasa menjalin kerjasama yang baik dengan para teknisi. Kondisi tersebut didukung dengan ketersediaan tenaga teknisi yang profesional dalam instansi dan dalam mengidentifikasi permasalahan yang terjadi, pegawai dibantu oleh teknisi yang ahli pada bidangnya sehingga berdampak nyata terhadap adanya inovasi dalam membantu menyelesaikan pekerjaan dan membantu sesama rekan kerja dengan mengeluarkan ide dan gagasan yang cukup menarik dalam menunjang peningkatan kinerja pegawai KPP Pratama Makassar Utara.

\section{e. Pengaruh dominan Terhadap Kinerja Pegawai}

Berdasarkan hasil penelitian, ditemukan bahwa pengaruh karakteristik individu lebih dominan dibandingkan pengaruh pemanfaatan teknologi informasi terhadap kinerja pegawai. Hasil tersebut dalam penelitian ini dapat dilihat dari nilai koefisien beta yang ditunjukkan karakteristik individu lebih tinggi yaitu dengan nilai beta $(\beta)$ sebesar 0,701 dan nilai koefisien beta yang ditunjukkan oleh pemanfaatan teknologi informasi yaitu dengan nilai 0,157.

Author : Wayan Sri Wijayanti dkk. (September, 2017). 14-28 


\section{JURNAL ORGANISASI DAN MANAJEMEN}

Issue 1 (September, 2017)

Hal ini menunjukkan bahwa variabel karakteristik individu dapat memengaruhi peningkatan kinerja pegawai kearah yang lebih tinggi dibandingkan variabel pemanfaatan teknologi informasi. Penyebab positif dan signifikannya dominan pengaruh karakteristik individu terhadap kinerja pegawai diakibatkan karena pegawai dalam bekerja mengeluarkan seluruh pengetahuan yang miliki dalam menyelesaikan pekerjaan sehingga berdampak pada rasa tanggung jawab yang besar terhadap setiap pekerjaan yang dijalankan dapat mempermudah pertukaran data dan infromasi dengan cepat sehingga memberikan kepuasan tersendiri bagi sesama rekan kerja. Kondisi tersebut didukung dengan menjaga rasa saling membantu dan menghargai terhadap sesama rekan kerja dan menunjukkan loyalitas kerja yang tinggi terhadap instansi dan rekan kerja saya sehingga berdampak nyata terhadap tuntutan agar pekerjaan terselesaikan dengan tepat waktu sehingga tidak menimbulkan permasalahan yang menghambat pegawai dalam menyelesaikan pekerjaannya pada KPP Pratama Makassar Utara.

\section{KESIMPULAN}

Karakteristik individu berpengaruh positif dan signifikan terhadap kinerja pegawai. Koefisien bertanda positif dan signifikannya pengaruh karakteristik individu terhadap kinerja pegawai diakibatkan karena pegawai dalam bekerja mengeluarkan seluruh kemampuan yang dimilikinya. Hal ini berarti meningkatnya ketelitian pegawai dalam menyelesaikan pekerjaan pada KPP Pratama Makassar Utara. Pemanfaatan teknologi informasi berpengaruh positif dan tidak signifikan terhadap kinerja pegawai. Koefisien bertanda positif dan tidak signifikan disebabkan karena pemanfaatan teknologi informasi belum mampu memengaruhi peningkatan kinerja pegawai. Kondisi tersebut menyebabkan kinerja pegawai dalam menyelesaikan pekerjaan belum memuaskan diakibatkan karena pengembangan inovasi, gagasan dan ide yang berdampak pada solidaritas pegawai dalam menjalin kerjasama yang baik dengan para teknisi pada KPP Pratama Makassar Utara. Karakterisik individu dominan berpengaruh dibandingkan pemanfaatan teknologi informasi terhadap kinerja pegawai. Kondisi tersebut disebabkan karena variabel karakteristik individu dapat memengaruhi peningkatan kinerja pegawai kearah yang lebih tinggi dibandingkan variabel pemanfaatan teknologi informasi. Penyebab positif dan signifikannya dominan pengaruh karakteristik individu terhadap kinerja pegawai diakibatkan karena pegawai dalam bekerja mengeluarkan seluruh pengetahuan yang miliki dalam menyelesaikan pekerjaan sehingga berdampak pada rasa tanggung jawab yang besar terhadap setiap pekerjaan yang dijalankan dapat mempermudah pertukaran data dan infromasi dengan cepat sehingga memberikan kepuasan tersendiri bagi sesama rekan kerja pegawai KPP Pratama Makassar Utara.

Disarankan kepada peneliti lanjutan agar Objek penelitian sebaiknya diperluas, sehingga hasil yang diperoleh lebih maksimal dan lebih dapat memberikan gambaran yang lebih jelas mengenai pengaruh karakteristik individu dan pemanfaatan teknologi informasi terhadap kinerja pegawai secara menyeluruh. Dalam hal waktu, hendaklah peneliti selanjutnya dapat memiliki waktu yang cukup untuk melakukan penelitian sehingga bisa mencapai hasil yang maksimal. Peneliti selanjutnya diharapkan dapat menambah beberapa variabel independen lainnya agar variabel tersebut mampu menjelaskan variabel dependen lebih besar dari penelitian sebelumnya sehingga mendapatkan hasil yang lebih akurat. 


\section{JURNAL ORGANISASI DAN MANAJEMEN}

Issue 1 (September, 2017)

Disarankan kepada KPP Pratama Makassar Utara untuk lebih meningkatkan pengimplementasian pemanfaatan teknologi informasi dalam menunjang penerapan sistem informasi yang lebih optimal.

\section{DAFTAR PUSATAKA}

Amalia, S., dan Rohman, A. (2010). Persepsi Pegawai Pajak terhadap Pemanfaatan Teknologi Informasi pada Kinerja Individual (Studi Kasus pada KPP Pratama Tegal) (Doctoral dissertation, Universitas Diponegoro).

Amin, Hamka., Sjahruddin, H., dan Syamsul, A. (2016). Pengaruh Kapasitas Sumber Daya Manusia dan Pemanfaatan Teknologi Informasi Konsekuensinya Pada Kinerja karyawan Pada KPP Pratama Makassar Utara. E-Library STIE YPBUP Bongaya

Aminah, S. (2016). Pengaruh Penerapan Teknologi Informasi Dan Saling Ketergantungan Organisasional Terhadap Penerapan Sistem Informasi Akuntansi Manajemen (Survey pada PT. INTI Persero) (Doctoral dissertation, Fakultas Ekonomi dan Bisnis Unpas).

Chintya, I. (2015). Pengaruh Pemanfaataan Teknologi Informasi Dan Sistem Pengendalian Intern Pemerintah Terhadap Kinerja Instansi Pemerintah Di Kota Solok (Studi pada SKPD Kota Solok). Jurnal Akuntansi, 3(1).

Hasanuddin, R., \& Sjahruddin, H. (2017). The Structure of Emotional Intelligence, Spiritual Intelligence and Its Relationship with Work Enthusiasm and Auditor Performance. World Journal of Business and Management, 3(1), 67.

Kardila, Tri., Sjahruddin, H., dan Heslina (2016) Dampak Karakteristik Pekerjaan dan Individu Pada Kepuasan Kerja Karyawan. E-Library STIE YPBUP Bongaya 2016 (2)

Mandasari, Y. E. (2016). Pengaruh Disiplin Kerja Terhadap Kinerja Pegawai Di Badan Pertanahan Nasional Kota Bandung (Doctoral Dissertation, Perpustakaan).

Moses, R. M. (2014). Pengaruh Karakteristik Individu Dan Karakteristik Pekerjaan Terhadap Prestasi Kerja Karyawwan (studi pada karyawan PT. Inti Bara Mandiri Tuban). Jurnal Administrasi Bisnis, 12(1).

Ovi engga Arista, O. (2015). Pengaruh Persepsi Atas Corporate Social Responsbility Terhadap Kepuasan Kerja Dan Komitmen Organisasi (Survey Pada Hotel Bintang V Di Yogyakarta) (Doctoral dissertation, Fakultas Ekonomi).

Peoni, H. (2014). Pengaruh karakteristik individu dan lingkungan kerja terhadap kinerja karyawan (Studi Pada PT. Taspen (Persero) Cabang Manado). Jurnal Administrasi Bisnis, 3(001).

Rachmawati, (2014). Pengaruh kapasitas sumber daya manusia, pemanfaatan Teknologi informasi, komitmen organisasi dan Pengendalian intern akuntansi terhadap Keterandalan dan ketepatwaktuan Pelaporan keuangan Pemerintah daerah studi pada dinas pendapatan, pengelolaan keuangan dan aset daerah Kabupaten boyolali.Skripsi.Surakarta. Fakultas Ekonomi Dan Bisnis Program Studi Akuntansi Universitas Muhammadiyah Surakarta.

Setiawan, A. (2012). Pengaruh Karakteristik Individu dan Faktor-Faktor Pekerjaan Terhadap Motivasi ( Studi Pada Karyawan CV . Bintang Timur Semarang ) The Influence of Individual Characteristics and Work Factors on Motivation (study on Employee CV . Bintang Timur Semarang ), 1-18.

Sholihin, M., \& Dwi, R. (2013). SEM-PLS with WarpPLS 3.0. Andi. Yogyakarta. 
Suwati, Y. (2013). Pengaruh Kompensasi dan Motivasi Kerja terhadap Kinerja Karyawan pada PT. Tunas Hijau Samarinda. Universitas Mulawarman. Samarinda, ..., 1(1), 41-55. 